\title{
Quantification of Technical Impacts and Environmental Benefits of Electric Vehicles Integration on Electricity Grids
}

\author{
J. A. Peças Lopes*, Senior Member, IEEE, F. J. Soares*, P. M. Rocha Almeida*, P. C. Baptista**, C. M. \\ Silva** and T. L. Farias** \\ * Instituto de Engenharia de Sistemas e Computadores do Porto (INESC Porto) and Faculdade de Engenharia da \\ Universidade do Porto (FEUP), Porto, Portugal. \\ ** Instituto de Engenharia Mecânica (IDMEC) and Instituto Superior Técnico da Universidade Técnica de Lisboa (IST- \\ UTL), Lisboa, Portugal.
}

\begin{abstract}
In this paper a typical electricity distribution network for a residential area in Portugal is used in order to assess the impact of integrating different levels of pure electric vehicles and plug-in hybrid vehicles in the grid and in pollutants emissions. First, the amount of vehicles that can be safely accommodated in the grid will be determined. Second, changes in pollutants emissions will be evaluated, by applying a vehicle full life cycle analysis.
\end{abstract}

Index Terms-electric and plug-in hybrid vehicles, grid integration, pollutants emissions and displacement, life cycle analysis.

\section{INTRODUCTION}

$\mathrm{T}$ HE reduction of the fossil fuel dependency in the road transportation sector, by replacing conventional vehicles by Electric Vehicles (EVs), can provide major advantages for urban areas, as it allows to improve the air quality and to reduce pollutants emissions. Nevertheless, only if proper integration strategies are defined will it be possible to accommodate large scale penetrations of EVs. Power flows, grid losses and voltage profile patterns along the grid will suffer considerable changes. Furthermore, this change in the mobility paradigm will centralize the pollutants emissions at generation plants' sites. All these problems might be minimized, for instance, if $\mathrm{EVs}$ charging takes place during off-peak periods such as valley hours.

In this paper a typical electricity distribution network for a residential area in Portugal is used in order to assess the impact of integrating different levels of EVs. With this study it is intended to evaluate the amount of EVs that can be safely accommodated in the grid, taking into account technical constraints, such as voltage profiles and power lines' congestion levels. Losses, changes in energy consumption and in pollutants emissions will be assessed in a second stage. In order to evaluate the environmental impacts of this solution, a life-cycle approach will be considered for the specific fleet under study, covering the materials cradle-to-grave life-cycle (including vehicle

Manuscript received in March 30, 2009. This work was supported in part by the MIT Portugal Program and Fundação para a Ciência e Tecnologia under Grants SFRH/BD/35191/2007, SFRH/BD/48491/2008 and SFRH/BD/47973/2008. assembling, maintenance, dismantling and recycling) and fuel life-cycle: Well-To-Tank (WTT) and Tank-To-Wheel (TTW). The materials life-cycle energy consumption and $\mathrm{CO}_{2}$ emissions are spread along the vehicle expected lifetime (in this case around 12 years). WTT accounts for energy consumption and $\mathrm{CO}_{2}$ emissions from primary energy resource extraction through the delivery of the fuel/energy source to the vehicle tank, while TTW accounts for the emissions and fuel consumption resulting from moving the vehicle through its drive cycle [1].

To achieve such an extended set of goals only two simplistic approaches for EV charging were used: no control and dual tariff system. The no control approach means that EV owners charge whenever they plug-in whereas the dual tariff is supposed to be attractive enough to make EV owners recharge in valley hours. Both these approaches are based on optimistic assumptions like the adoption of constant charging frequencies, which does not represent a worst case scenario, as it will be detailed in section III.

\section{REGION CHARACTERIZATION}

\section{A. Grid Architecture}

Fig. 1 describes the electricity distribution network used in this research, corresponding to a typical semi-urban, 15 $\mathrm{kV}$, Medium Voltage (MV) grid. The clients of this type of grid are mainly residential consumers, providing a good platform for studying the impacts of EVs' integration. It was assumed that each MV/LV (Low Voltage) transformer, represented by a triangular shape in the figure, plus the downstream LV grid, have the capability to accommodate all the EVs considered in each scenario without suffering any significant impacts. This assumption allows focusing the study in the MV grid, as it is intended with this paper.

This grid despite being meshed is explored using a radial configuration. There are two feeders energizing two separate areas, represented by the round shapes in the figure, whose specified voltage is 1.05 p.u.. Typically, associated to these networks there are two main problems that arise with the increase in load. The branches around the feeding points are expected to reach high congestion levels, while the buses more electrically distant from the feeding points are expected to face voltage drop problems. 


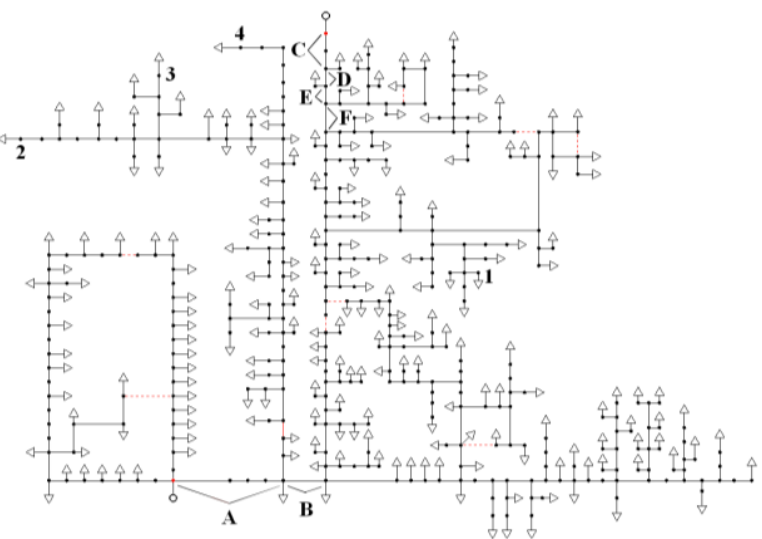

Fig. 1. Medium voltage distribution network $(15 \mathrm{kV})$. The numbers 1 to 5 identify the buses that are more prone to having voltage problems.

The letters A to F identify the most congested branches.

In order to evaluate the impacts in terms of load profiles, a 24 hours simulation was performed, considering two typical daily diagrams, one for a typical summer day and other for a winter day. For the grid under study, the typical load diagrams for Portuguese consumers are depicted in Fig. 2 and 3. The household, commercial and industrial diagrams were combined taking into account the proportion of installed power related with each type of these consumers. Thus, the final diagram has a contribution of nearly $66 \%$ of the household, $28 \%$ of the commercial and $6 \%$ of the industrial, as these are the proportions of installed power related with each type of load within this grid. The consumption in this grid for a summer day is $309.3 \mathrm{MWh}$, while for the winter day is 355.8 MWh. The yearly energy consumption is 121.4 GWh, which represents $0.33 \%$ of all the energy consumed in Portugal during one year.

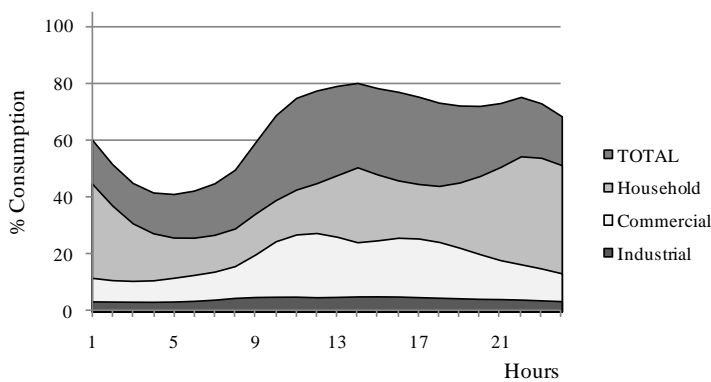

Fig. 2. Load profile during a typical summer day.

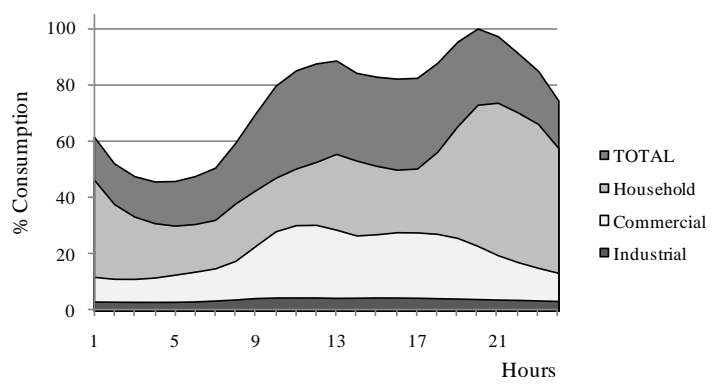

Fig. 3. Load profile during a typical winter day.

\section{B. Fleet of Light-Duty Vehicles}

The population of the selected region is around 31500 inhabitants, which combined with the average Portuguese vehicle density of 510 vehicles per 1000 inhabitants [2], [3] corresponds to an approximate fleet of 16000 vehicles.

The Portuguese fleet characterization in terms of diesel/gasoline distribution, weight and displacement vehicles' distribution was assumed for this region as represented in Table I.

TABLE I

FLEET CHARACTERIZATION - FUEL DISTRIBUTION AND DISPLACEMENT

\begin{tabular}{|c|c|c|c|c|}
\hline Displacement & Number & Total & Global \% & \% Fuel \\
\hline \multicolumn{5}{|c|}{ Gasoline } \\
\hline$<1.41$ & 6948 & \multirow{3}{*}{8497} & $43 \%$ & \multirow{3}{*}{$53 \%$} \\
\hline $1.4-2.01$ & 1393 & & $9 \%$ & \\
\hline$>2.01$ & 155 & & $1 \%$ & \\
\hline \multicolumn{5}{|c|}{ Diesel } \\
\hline$<2.01$ & 5356 & \multirow{2}{*}{7436} & $33 \%$ & \multirow{2}{*}{$46 \%$} \\
\hline$>2.01$ & 2080 & & $13 \%$ & \\
\hline \multicolumn{5}{|c|}{ LPG } \\
\hline$>2.01$ & \multicolumn{2}{|c|}{67} & \multicolumn{2}{|c|}{$0.42 \%$} \\
\hline Total & \multicolumn{2}{|c|}{16000} & \multicolumn{2}{|c|}{$100 \%$} \\
\hline
\end{tabular}

Additionally, a typical annual and daily mileage of respectively 12800 and $35 \mathrm{~km}$ was assumed [4]. To estimate the specific fleet fuel consumption and derived emissions COPERT 4 [5] was used, which is an European tool for estimating the emissions and fuel consumption of specific fleets (with conventional vehicle technologies). For COPERT a mix of urban (24\% of total distance), rural (57\% of total distance) and highway (19\% of total distance) driving was considered.

Results obtained for the conventional fleet fuel consumption and annual emissions of carbon dioxide $\left(\mathrm{CO}_{2}\right)$, carbon monoxide $(\mathrm{CO})$, hydrocarbons $(\mathrm{HC})$, nitrogen oxides $\left(\mathrm{NO}_{\mathrm{x}}\right)$ and particulate matter $(\mathrm{PM})$ are presented in Table II, according to the categories of vehicle considered.

TABLE II

ANNUAL TTW CHARACTERIZATION FOR THIS SPECIFIC FLEET IN TERMS OF FUEL CONSUMPTION AND EMISSIONS

\begin{tabular}{ccccccccc}
\hline \hline \multirow{2}{*}{ Vehicle category } & \multicolumn{3}{c}{ Fuel consumption } & & \multicolumn{5}{c}{ Emissions (ton) } \\
& $\mathbf{1} / \mathbf{1 0 0 k m}$ & $\mathbf{G W h}$ & $\mathbf{C O}_{2}$ & $\mathbf{C O}$ & $\mathbf{H C}$ & $\mathbf{N O}$ & $\mathbf{P M}$ \\
\hline Gasoline $<1,41$ & 6.9 & 45.3 & 11751 & 324 & 47 & 45 & 0.15 \\
Gasoline $1,4-2,01$ & 8.2 & 12.3 & 3211 & 51 & 8 & 7 & 0.03 \\
Gasoline $>2,01$ & 10.3 & 1.8 & 459 & 4 & 0.4 & 0.5 & 0.003 \\
Diesel $<2,01$ & 6.1 & 51.3 & 13687 & 17 & 3 & 57 & 5.68 \\
Diesel $>2,01$ & 7.9 & 23.0 & 6104 & 9 & 3 & 20 & 2.83 \\
LPG & $2.9^{\mathrm{a}}$ & 0.77 & 175 & 3 & 1 & 1 & 0 \\
\hline Total & $\mathbf{7 . 2}^{\mathrm{b}}$ & $\mathbf{1 3 4 . 5}$ & $\mathbf{3 5 4 0 0}$ & $\mathbf{4 0 6}$ & $\mathbf{6 1}$ & $\mathbf{1 3 0}$ & $\mathbf{8 . 6 9}$ \\
\hline \hline
\end{tabular}

${ }^{\mathrm{a}}$ in $\mathrm{m}^{3}$ of liquid propane gas per $100 \mathrm{~km} .{ }^{\mathrm{b}}$ gasoline equivalent.

Summarizing, the light-duty conventional road transport sector of this specific region consumes 134.5 GWh of fossil fuel energy and is responsible for a global annual $\mathrm{CO}_{2}$ emission of 35400 ton and for a local emission of 406 ton of $\mathrm{CO}, 61$ ton of $\mathrm{HC}, 130$ ton of $\mathrm{NO}_{\mathrm{x}}$ and 8.7 ton of PM.

\section{Electric Generation Mix and Emissions per $\mathrm{kWh}$}

In Portugal the electricity energy generation mix (in the year 2006), includes: hydro generation (24\%), wind generation $(6 \%)$, energy produced in coal-fired power stations (30\%), energy produced in oil-fired power stations $(11 \%)$, generation from natural gas-fired power stations $(25 \%)$ and generation from biomass-fired power stations (4\%) [6]. This generation mix, combined with Spanish imports of around $20 \%$, yields an emission factor of ca. $497 \mathrm{~g} / \mathrm{kWh}$ and an energy ratio of $2.33 \mathrm{MWh}$ of primary energy per MWh of produced electric energy. Furthermore, carbon monoxide (CO), hydrocarbons (HC), nitrogen oxides $\left(\mathrm{NO}_{\mathrm{x}}\right)$ and particulate matter $(\mathrm{PM})$ emissions factors for the total electricity production were also considered $(0.10,1.20,1.48$ and $0.17 \mathrm{~kg} / \mathrm{MWh}$ respectively) [7]. This data is used to evaluate the pollutants' emissions related with electricity generation. 


\section{SCENARIO CHARACTERIZATION}

For assessing the impact of electric/hybrid plug-in vehicles on the electric grid, three new technologies of EVs were considered with the following characteristics:

--Plug-in hybrid (PH): Ni-MH battery of $6 \mathrm{kWh}$, electric motor of $60 \mathrm{~kW}$, internal combustion engine of 40 $\mathrm{kW}$, generator of $40 \mathrm{~kW}$ and total weight of $1120 \mathrm{~kg}$;

--Medium size electric vehicle (EV1): Ni-MH battery of $12 \mathrm{kWh}$, electric motor of $65 \mathrm{~kW}$, total weight $1214 \mathrm{~kg}$;

--Large size electric vehicle (EV2): Ni-MH battery of $24 \mathrm{kWh}$, electric motor of $75 \mathrm{~kW}$, total weight $1393 \mathrm{~kg}$.

These vehicles have a total power-to-weight ratio of $55 \mathrm{~W} / \mathrm{kg}$ since this is representative of the top sales of new vehicles sold in Portugal, with which these new technologies will probably have to compete when they start penetrating the market. Additionally, it guarantees that similar vehicle performances are being compared.

The designed scenarios for the plug-in hybrid and electric vehicles are presented in Table III.

TABLE III

DESIGNED SCENARIOS FOR THE PENETRATION OF ELECTRIC VEHICLES Scenarios $\quad$ Vehicle penetration (\%) $\quad$ Number of vehicles

\begin{tabular}{ccccccccc}
\hline \hline \multirow{2}{*}{ Scenarios } & \multicolumn{3}{c}{ Vehicle penetration (\%) } & \multicolumn{4}{c}{ Number of vehicles } \\
\cline { 2 - 8 } & Total fleet replaced & PH & EV1 & EV2 & PH & EV1 & EV2 & Total \\
\hline $\begin{array}{c}\text { Base } \\
\text { scenarios }\end{array}$ & 0 & 0 & 0 & 0 & 0 & 0 & 0 & 0 \\
$\begin{array}{c}\text { Low } \\
\text { penetration }\end{array}$ & 10 & 16 & 42 & 42 & 256 & 672 & 672 & 1600 \\
$\begin{array}{c}\text { Medium } \\
\text { penetration }\end{array}$ & 30 & 20 & 40 & 40 & 960 & 1920 & 1920 & 4800 \\
$\begin{array}{c}\text { High } \\
\text { penetration }\end{array}$ & 50 & 24 & 38 & 38 & 1920 & 3040 & 3040 & 8000 \\
\hline \hline
\end{tabular}

The base scenario corresponds to the present situation that was described earlier. For the low, medium and high penetration scenarios the number of electricity based vehicles continuously increases.

Since COPERT 4 does not include any of the new vehicle technology considered, for simulating the daily commuting journeys of these new three vehicle technologies ADVISOR vehicle simulation software [8] was used. ADVISOR is a micro-simulating tool to estimate the performance and fuel economy of conventional and advanced new vehicle technologies. A real measured driving cycle was used, representing a mix of urban $(24 \%$ of total distance covered with speed below $50 \mathrm{~km} / \mathrm{h}$ ), rural ( $57 \%$ of total distance with speed between 50 and $90 \mathrm{~km} / \mathrm{h}$ ), and highway (19\% of total distance with speed higher than $90 \mathrm{~km} / \mathrm{h}$ ) driving. Fig. 4 shows the driving cycle speed profile and respective grade. The vehicle occupancy was assumed to be of one single person (weighting $70 \mathrm{~kg}$ ). ADVISOR results allow estimating tailpipe emissions of $\mathrm{HC}, \mathrm{CO}, \mathrm{NO}_{\mathrm{x}}, \mathrm{CO}_{2}$ and $\mathrm{PM}$ for the gasoline plug-in hybrid and electricity consumption/frequency of recharging for PH, EV1 and EV2. It was found that the vehicles autonomy regarding electric consumption from the battery was $30 \mathrm{~km}$ for the $\mathrm{PH}, 75 \mathrm{~km}$ for EV1 and $150 \mathrm{~km}$ for EV2. The charging frequency and charging energy computed was, respectively, $3.3 \mathrm{kWh}$ on a daily basis, $10.9 \mathrm{kWh}$ every two days and $22.4 \mathrm{kWh}$ every 4 days.

As mentioned before an optimistic assumption regarding charging frequencies was done. As each EV charges only after a certain period of time, on average, per day, their load will be the total load distributed over the number of days between charges, e.g., EV2 charges 22.4 kWh every 4 days, thus the average daily charge will be $22.4 \mathrm{kWh}$ times the number of EV2 vehicles over 4 days.
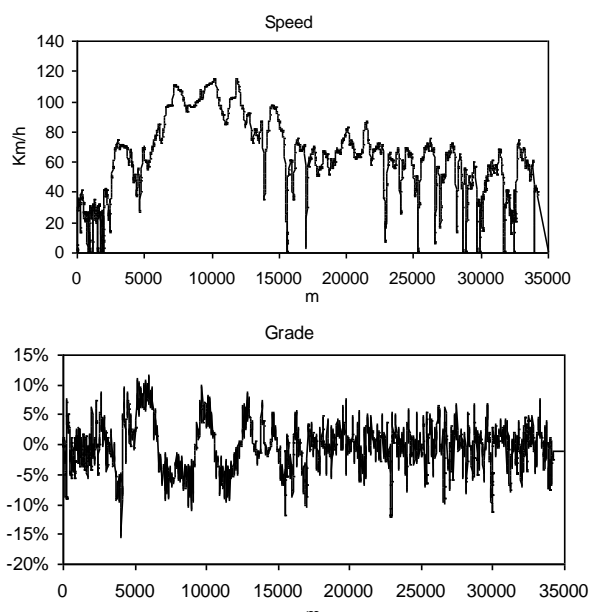

Fig. 4. Drive cycle and respective grade.

Concerning the additional load due to EVs charging, Fig. 5 and 6 show its value along one entire day for the two strategies adopted: with no control at all and with the dual tariff system, respectively. As one can observe in Fig. 6 , the dual tariff system considered valley hours to occur between $2 \mathrm{~h}$ and $8 \mathrm{~h}$.

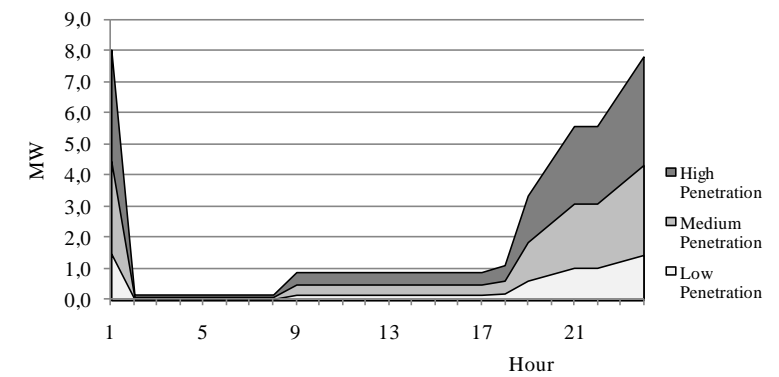

Fig. 5. EVs consumption along the day with the no control approach [9].

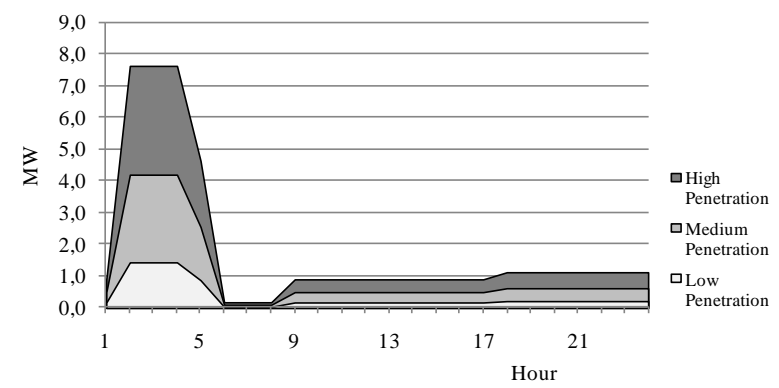

Fig. 6. EVs consumption along the day with a dual tariff system.

The new fleet for each scenario was characterized in terms of energy consumption and emissions. It was considered that the electric/plug-in hybrids vehicles introduced successively replaced older conventional vehicles (more specifically, vehicles bought before 2000).

\section{IMPACT ASSESSMENT}

To establish a proper comparison between the several created scenarios, the results regarding network impacts were computed using PSS/ETM, being the changes in energy consumption and pollutants emissions compiled into tables and figures as presented along the following subsections.

In terms of materials cradle-to-grave GREET life-cycle software [10] was used while for the conventional fuels life-cycle the E3 database [11] was adopted. 


\section{A. Load Diagrams}

As expected, all the load diagrams suffer increasing changes as the number of EVs considered raises.

In the summer day, with no control (Fig. 7), the peak load increases along the scenarios and the peak hour shifts from $14 \mathrm{~h}$ to $24 \mathrm{~h}$ in the last one.

घHigh Penetration Scenario $\quad \square$ Medium Penetration Scenario

口Low Penetration Scenario $\quad$ 口Base Scenario

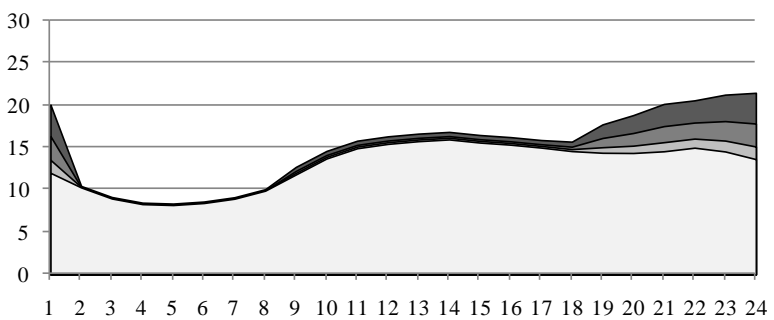

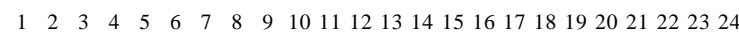

Fig. 7. Summer day load diagram with no control approach (MW).

When the dual tariff is applied, something unexpected happens (Fig.8). Despite the peak load being kept almost the same, the peak hour suffers a major change. It shifts from $14 \mathrm{~h}$ to $2 \mathrm{~h}$.

Concerning the winter day, when no control is applied, the peak load increases along the scenarios and the peak hour suffers a slight shift from $20 \mathrm{~h}$ to $21 \mathrm{~h}$ (Fig. 9). When the dual tariff is applied (Fig. 10), something similar to the summer day case happens.

口High Penetration Scenario a Medium Penetration Scenario

口Low Penetration Scenario $\quad$ 口Base Scenario

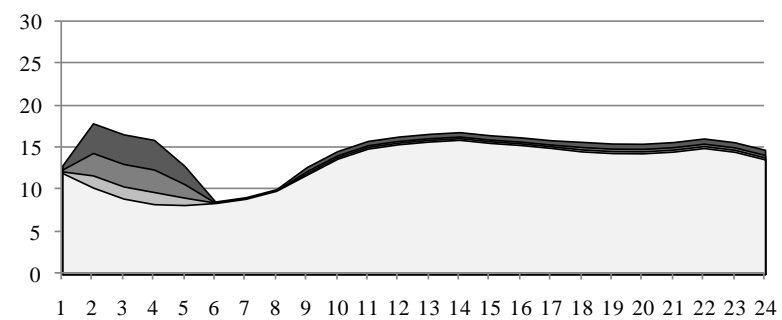

Fig. 8. Summer day load diagram with a dual tariff system (MW).

- High Penetration Scenario aMedium Penetration Scenario 口Low Penetration Scenario $\quad$ 口Base Scenario

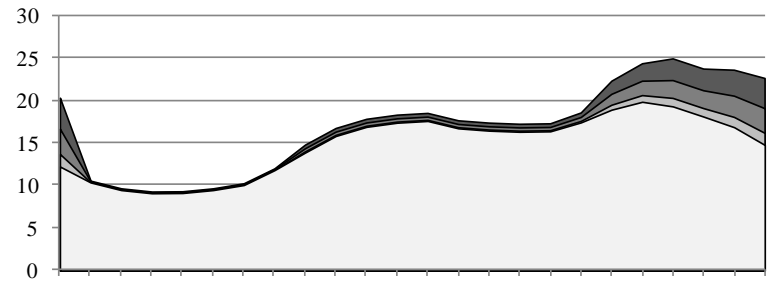

$1 \quad 2 \quad 3 \quad 4 \quad 5 \quad 6 \quad 7 \quad 8 \quad 9 \quad 101112131415161718192021222324$ Fig. 9. Winter day load diagram with no control approach (MW).

घHigh Penetration Scenario $\quad$ घMedium Penetration Scenario 口Low Penetration Scenario $\quad$ 口Base Scenario

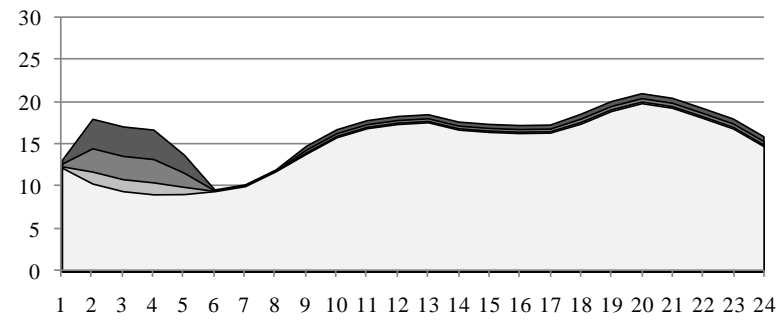

Fig. 10. Winter day load diagram with a dual tariff system (MW).
Despite the peak load and the peak hour being kept nearly constant along the scenarios, there is a considerable increase in electricity consumption during night time. For more than $50 \%$ of EVs, the peak hour in the winter is likely to change from $20 \mathrm{~h}$ to $2 \mathrm{~h}$, just as happened in the summer day.

\section{B. Network Voltage Profiles}

Looking at Table IV it is possible to evaluate the effects of EVs penetration in the voltage profiles, at peak hour, for some of the buses more electrically distant to the feeding points. As the number of EVs increases, the voltages in these buses drop to values far below the reference bus voltage ( 0.95 p.u., represented by the dashed line in Fig. 11). As the bottlenecks occurred first in the winter scenarios the tabled results are related only to those.

The average voltage drop in the four buses for the typical summer day, when comparing the base scenario with the high penetration one, is $3.26 \%$ when no control is imposed and $1.26 \%$ when the dual tariff system is applied. For the typical winter day, these values change to $3.15 \%$ and $0.68 \%$, respectively.

Bus 1 , which is the electrically farthest bus from the feeding point, experiences the largest voltage change (Fig. $11)$. When no control is applied it reaches values below the acceptable threshold. Thus, with the no control approach, for approximately $10 \%$ penetration it presents a bottleneck for EV integration, demanding new investments in grid reinforcement if more EVs are sought, whereas with dual tariff the allowable EV integration is 13\%. All the other grid nodes not included in Table IV suffer similar changes in their voltages, but the four presented are those with bigger drops.

TABLE IV

\begin{tabular}{ccccccccc}
\multicolumn{8}{c}{ VOLTAGE LEVELS - WINTER DAY (p.u.) } \\
\hline \hline \multirow{2}{*}{ Bus } & $\begin{array}{c}\text { Base } \\
\text { Scenario }\end{array}$ & \multicolumn{2}{c}{$\begin{array}{c}\text { Low } \\
\text { Penetration }\end{array}$} & \multicolumn{2}{c}{$\begin{array}{c}\text { Medium } \\
\text { Penetration }\end{array}$} & \multicolumn{2}{c}{$\begin{array}{c}\text { High } \\
\text { Penetration }\end{array}$} \\
\hline & & $\mathrm{NC}^{\mathrm{a}}$ & $\mathrm{DT}^{\mathrm{b}}$ & $\mathrm{NC}^{\mathrm{a}}$ & $\mathrm{DT}^{\mathrm{b}}$ & $\mathrm{NC}^{\mathrm{a}}$ & $\mathrm{DT}^{\mathrm{b}}$ \\
\cline { 3 - 9 } 1 & 0.951 & 0.945 & 0.950 & 0.936 & 0.947 & 0.921 & 0.944 \\
2 & 0.957 & 0.952 & 0.956 & 0.942 & 0.953 & 0.926 & 0.950 \\
3 & 0.958 & 0.953 & 0.957 & 0.943 & 0.954 & 0.927 & 0.951 \\
4 & 0.960 & 0.955 & 0.958 & 0.945 & 0.956 & 0.930 & 0.953 \\
\hline \hline \multicolumn{8}{c}{${ }^{\mathrm{a}}$ No Control. ${ }^{\mathrm{b}}$ Dual Tariff. }
\end{tabular}

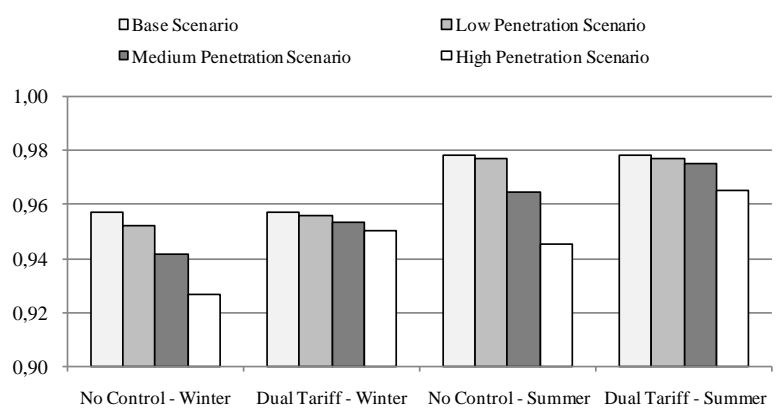

Fig. 11. Bus 1 voltage in the peak hour of each scenario (p.u.).

\section{Network Branches Congestion Levels}

Table $\mathrm{V}$ shows the congestion levels evolution, in six of the most loaded branches, for the winter and summer typical days, at the peak hour. As expected, the most problematic spots are located near the feeding points as all 
the power demanded flows through the lines adjacent to it. Again, the results shown in the table are only related with the winter scenarios as these are the ones where congestions occur first.

TABLE V

BRANCHES CONGESTION LEVELS - WINTER DAY (\%)

\begin{tabular}{cccccccc}
\hline \multicolumn{1}{c}{$\begin{array}{c}\text { Line } \\
\text { Section }\end{array}$} & $\begin{array}{c}\text { Base } \\
\text { Scenario }\end{array}$ & \multicolumn{2}{c}{$\begin{array}{c}\text { Low } \\
\text { Penetration }\end{array}$} & \multicolumn{2}{c}{$\begin{array}{c}\text { Medium } \\
\text { Penetration }\end{array}$} & \multicolumn{2}{c}{$\begin{array}{c}\text { High } \\
\text { Penetration }\end{array}$} \\
\hline & & $\mathrm{NC}^{\mathrm{a}}$ & $\mathrm{DT}^{\mathrm{b}}$ & $\mathrm{NC}^{\mathrm{a}}$ & $\mathrm{DT}^{\mathrm{b}}$ & $\mathrm{NC}^{\mathrm{a}}$ & $\mathrm{DT}^{\mathrm{b}}$ \\
\cline { 3 - 9 } $\mathrm{A}$ & 80.2 & 84.2 & 81.2 & 92.7 & 83.1 & 105.3 & 85.6 \\
B & 69.9 & 73.4 & 70.8 & 80.7 & 72.5 & 91.3 & 74.5 \\
C & 64.2 & 67.3 & 64.9 & 73.7 & 66.4 & 83.5 & 68.3 \\
D & 61.8 & 64.6 & 62.5 & 70.6 & 63.9 & 79.4 & 65.6 \\
E & 60.6 & 63.4 & 61.3 & 69.1 & 62.6 & 77.5 & 64.3 \\
F & 49.8 & 51.6 & 50.3 & 55.2 & 51.2 & 60.8 & 52.3 \\
\hline \hline
\end{tabular}

The biggest changes in congestion levels were observed in branches A and B. In the summer day, their ratings increase by $43.2 \%$ when no control is imposed and by $19.0 \%$ with the dual tariff system.

In the winter day the congestion level increase was lower, $31.0 \%$ and $6.7 \%$, respectively. However, in winter, the maximum allowable rating in line section $\mathrm{A}$ is surpassed (Fig. 13).

In order to safely and reliably explore this grid, line section A should be reinforced somewhere between the medium and the high penetration scenarios. However, as this happened at a larger penetration level of EVs, when comparing with the voltage level analysis, the grid reinforcement would have already been needed to suppress the voltage problems identified.

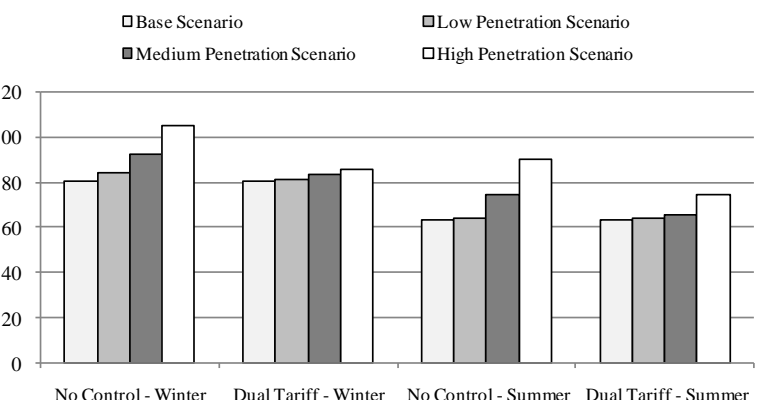

Fig. 12. Congestion levels of line section $\mathrm{A}$ in the peak hour of each scenario $(\%)$.

\section{Energy Consumption and Emissions Changes}

Assuming that it is possible to solve the technical problems identified before, larger EV penetration levels can then be considered. Thus, a sensitivity analysis regarding environmental impacts for all the scenarios defined before was performed, accounting only the energy expenditures that concern both conventional and electric vehicles.

Relating to EVs, the PH configuration runs the internal combustion engine when high power events occur. This represents a gasoline consumption of $2.51 / 100 \mathrm{~km}$ and $\mathrm{HC}$ emissions of $138 \mathrm{mg} / \mathrm{km}, \mathrm{CO}$ emissions of $2.8 \mathrm{~g} / \mathrm{km}$ and $\mathrm{NO}_{\mathrm{x}}$ emissions of $123 \mathrm{mg} / \mathrm{km}$, whereas full electric vehicles, of course, have no gasoline consumption.

For the TTW stage, the fleet's annual fuel consumption according to the vehicle type is presents in Table VI.
TABLE VI

ANNUAL TTW DISAGGREGATED TOTAL FLEET FUEL CONSUMPTION (GWh) FOR THE THREE SCENARIOS

\begin{tabular}{|c|c|c|c|c|}
\hline \multirow{2}{*}{ Vehicle } & \multirow{2}{*}{ Energy source } & \multicolumn{3}{|c|}{ TTW } \\
\hline & & Low & Medium & High \\
\hline Conventional & Gasoline/Diesel/LPG & 124.9 & 102.6 & 75.3 \\
\hline \multirow{2}{*}{ PH } & Gasoline & 0.7 & 2.7 & 5.5 \\
\hline & Electricity & 0.3 & 1.2 & 2.3 \\
\hline EV1 & Electricity & 1.3 & 3.8 & 6.1 \\
\hline EV2 & Electricity & 1.4 & 3.9 & 6.2 \\
\hline \multicolumn{2}{|r|}{ Total } & 129 & 114 & 95 \\
\hline
\end{tabular}

As expected, the conventional fuels consumption decreases along the three scenarios while the electricity consumption increases. As more EVs are introduced, less old vehicles (with higher annual mileages) are replaced and consequently the reduction on TTW energy consumption is higher. It is also worth mentioning that, in spite of the fact that the PH considered is mostly powered by electricity, in order to achieve higher speeds, this plugin has to use its internal combustion engine, which is reflected in a 58:42 ratio between gasoline and electricity.

By analyzing Table VII, it is possible to conclude that the replacement of older vehicles by less polluting ones allows a significant reduction in terms of local pollution. These values were determined using the average emission values described in section II. From the values shown in the table it is possible to conclude that reduction in pollutants emissions are particularly significant for local TTW emissions with 26-60\% reductions for $\mathrm{CO}, 33-77 \%$ for $\mathrm{HC}, 18-54 \%$ for $\mathrm{NO}_{\mathrm{x}}$ and $18-61 \%$ for PM. Even considering the WTT global emissions from additional electricity generation $\mathrm{CO}, \mathrm{HC}$ and $\mathrm{NO}_{\mathrm{x}}$ emissions still decrease.

TABLE VII

ANNUAL WTT AND TTW FUEL CONSUMPTION (FC) AND EMISSIONS FOR THE CONSIDERED SCENARIOS

\begin{tabular}{ccccccccccccc}
\hline \hline \multirow{2}{*}{ Scenario } & \multicolumn{2}{c}{$\mathrm{FC}(\mathrm{TJ})$} & \multicolumn{2}{c}{$\mathrm{CO}_{2}$ (kton) } & \multicolumn{2}{c}{$\mathrm{CO}$ (ton) } & \multicolumn{3}{c}{$\mathrm{HC}$ (ton) } & \multicolumn{2}{c}{$\mathrm{NO}_{\mathrm{x}}$ (ton) } & \multicolumn{2}{c}{ PM (ton) } \\
& WTT & TTW & WTT & TTW & WTT & WTT & WTT & TTW & WTT & TTW & WTT & TTW \\
\hline Basecase & 56 & 484 & 5 & 35 & 0 & 0.79 & 0 & 61 & 0 & 130 & 0.79 & 8.69 \\
Low & 77 & 463 & 6 & 33 & 0 & 1.26 & 4 & 41 & 4 & 107 & 1.26 & 7.10 \\
Medium & 121 & 411 & 8 & 28 & 1 & 2.15 & 11 & 22 & 13 & 81 & 2.15 & 5.12 \\
High & 164 & 343 & 11 & 21 & 1 & 2.99 & 18 & 14 & 22 & 60 & 2.99 & 3.43 \\
\hline \hline
\end{tabular}

After combining the materials cradle-to-grave with the fuel TTW and WTT, the energy and $\mathrm{CO}_{2}$ emissions distributions were obtained (Fig. 13 and 14).

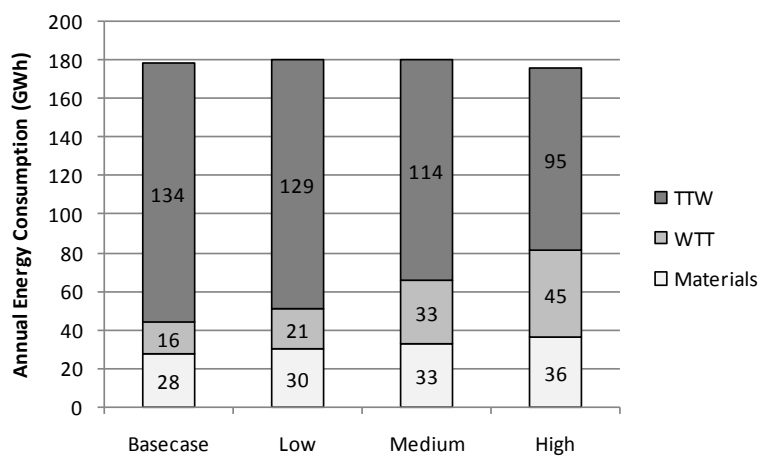

Fig. 13. Annual fleet's life cycle results for materials, WTT and TTW regarding energy consumption in the considered scenarios.

A clear shift from the magnitude of TTW to the WTT results is observed with the increasing penetration of electricity based vehicles. Additionally, as the number of these vehicles increases the materials stage also gains importance, since electric vehicles manufacturing is more energy intensive. 


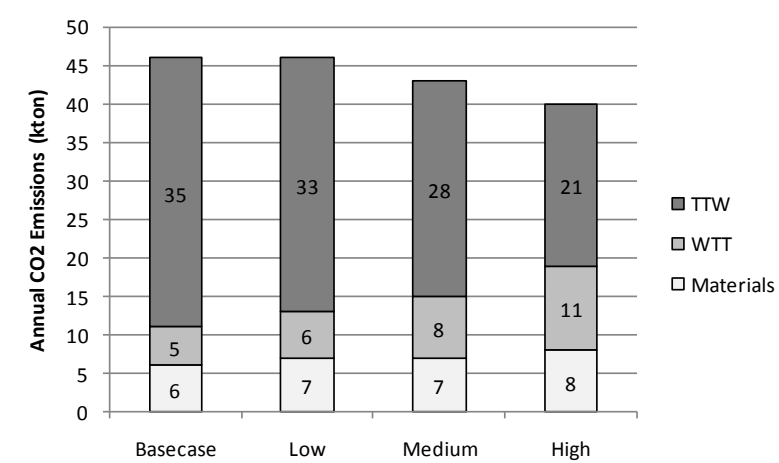

Fig. 14. Annual fleet's life cycle results for materials, WTT and TTW regarding $\mathrm{CO}_{2}$ emissions in the considered scenarios.

In terms of the annual energy consumption it slightly increases for the low and medium scenarios but decreases for the higher penetration one. The initial increase is justified with the additional electricity (WTT) and the decrease with the substitution of higher mileage vehicles and due to increasing penetration of more efficient ones. With the imposed EU renewable energy targets, the WTT tendency can be substantially reduced in the future.

As for $\mathrm{CO}_{2}$ emissions, the fossil fuels consumption in transportation decreases, which considerably lowers $\mathrm{CO}_{2}$ emissions. Even the slight increase in WTT emissions from increasing electricity consumption can be reduced in the future if the vehicles' batteries are charged during periods where there is a high renewable energy share (as it might happen in night periods). However, in the given circumstances, the medium and high scenarios results are only potential ones, since grid technical constraints limit to $13 \%$ the integration level of EVs.

\section{E. Network Losses}

Looking at Table VIII it is possible to evaluate the effects of EVs penetration in the value of the energy losses within the grid. As the number of EVs increases, the electric power flowing along the grid raises, evidently the same happens to losses, as losses are directly proportional to the square of the current.

TABLE VIII

DAILY AND YEARLY LOSSES

\begin{tabular}{cccc}
\hline \hline & $\begin{array}{c}\text { Winter Day } \\
(\mathrm{MWh})\end{array}$ & $\begin{array}{c}\text { Summer Day } \\
(\mathrm{MWh})\end{array}$ & $\begin{array}{c}\text { Yearly } \\
(\mathrm{GWh})\end{array}$ \\
\hline Base Scenario & 16.53 & 12.10 & 5.22 \\
Low Penetration - No Control & 17.49 & 12.87 & 5.54 \\
Low Penetration - Dual Tariff & 17.19 & 12.68 & 5.45 \\
Medium Penetration - No Control & 19.55 & 14.54 & 6.22 \\
Medium Penetration - Dual Tariff & 18.64 & 13.97 & 5.95 \\
High Penetration - No Control & 22.45 & 16.93 & 7.19 \\
High Penetration - Dual Tariff & 20.72 & 15.85 & 6.67 \\
\hline \hline
\end{tabular}

The increase in yearly losses, when comparing the base scenario with the high penetration one, is of $1.96 \mathrm{GWh}$ when no control is imposed to EVs and of $1.45 \mathrm{GWh}$ when dual tariff system is applied. Nevertheless, the EVs influence in energy losses goes beyond the values presented above, as they only refer to the MV level. In turn, to feed EVs, the electric energy must flow from the generation facilities, located at the higher voltage levels of the electric power system, to the vehicles' batteries connected at the LV level. Such fact was taken into account when addressing the WTT and TTW analysis by using an average value for Portugal of $8 \%$.

\section{CONCLUSIONS}

Concerning grid impacts of EV penetration it is clear that if a "dumb" charging approach is implemented the amount of EVs that will be possible to accommodate without grid reinforcement is smaller than if a smarter approach is used. Simply by using a dual-tariff approach it was possible to improve voltage profiles enabling EV integration growth from $10 \%$ to $13 \%$, without any reinforcement investments. There were also positive impacts of this approach in branches congestion levels.

The aforementioned results lead to the conclusion that a bolder strategy should be sought by defining an active charging management approach, possibly integrated with a smart metering [12] and microgrid control concepts [12]. In this way a larger share of EVs can be integrated without the need for grid reinforcement.

Then, regarding environmental impacts, EVs have a clear advantage in terms of local air quality (up to $77 \%$ emission reductions of $\mathrm{HC}, \mathrm{CO}, \mathrm{NO}_{\mathrm{x}}$ and $\left.\mathrm{PM}\right)$. In terms of global environment impact, $\mathrm{CO}_{2}$ emissions can be reduced by up to $40 \%$ when running the vehicles, but this percentage is only $15 \%$ if a full cradle-to-grave analysis is accounted for.

\section{REFERENCES}

[1] P. Moon, A. Burnham, M. Wang, "Vehicle-Cycle Energy and Emission Effects of Conventional and Advanced Vehicles", SAE Technical Paper Series, 2006-01-0375, 2006.

[2] Instituto Nacional de Estatística, "Population Statistics", 2008.

[3] Associação Automóvel de Portugal (ACAP), "Statistics for the Portuguese Automotive fleet", 2006.

[4] Carlos Lima Azevedo, "Métodos de estimativa de volumes anuais de tráfego rodoviário - um modelo para Portugal", Master Thesis in Transports, IST, Universidade Técnica de Lisboa, 2008.

[5] D. Gkatzoflias, C. Kouridis, L. Ntziachristos, Z. Samaras, "COPERT 4, computer programme to calculate emissions from road transport", ETC/AEM, 2007.

[6] Eurostat - Energy and Environment Indicators, "EUROPA Eurostat - Data Navigation Tree", November 2008.

[7] C. A. Lewis, "Fuel and Energy Production Emission Factors, MEET Project: Methodologies for Estimating Air Pollutant Emissions from Transport", ETSU Report, No. R112, 1997.

[8] K. Wipke, M. Cuddy, S. Burch, "ADVISOR 2.1: A User Friendly Advanced Powertrain Simulation Using a Combined Backward/Forward Approach", IEEE Transactions on Vehicular Technology 48, pp. 1751-1761, 1999.

[9] W. Kempton, J. Tomic, S. Letendre, A. Brooks, T. Lipman, "Vehicle-to-Grid Power: Battery, Hybrid, and Fuel Cell Vehicles as Resources for Distributed Electric Power in California", unpublished, 2001.

[10] A. Burnham, M. Wang, Y. Wu, "Development and Applications of Greet 2.7 - The Transportation Vehicle-Cycle Model", Energy Systems Division, Argonne National Laboratory, 2007.

[11] General Motors, "Well-To-Wheel Analysis of Energy Use and Greenhouse Gas Emissions of Advanced Fuel / Vehicle Systems A European Study", Germany, 2002.

[12] L. Cunha, J. A. Peças Lopes et.al., "InovGrid Project Distribution network evolution as a decisive answer to new electrical sector challenges, Proc. CIRED seminar, June 2008.

[13] J. A. Peças Lopes, C. L. Moreira, A. G. Madureira, "Defining Control Strategies for MicroGrids Islanded Operation", IEEE PWRS - IEEE Transactions on Power Systems, vol.21, no.2, pp.916-924, June 2006. 